\title{
Motivational Factors and Learning Styles in Acquisition of Global Language and Business Skills in Multicultural Education
}

\author{
Ma. Hazel Ramos ${ }^{1}$ and Chung-Yeol Park ${ }^{2}$ \\ ${ }^{1,2}$ Department of International Business Management, Korea Nazarene University, \\ Wolbong-Ro 48, Seobuk-gu, Cheonan-si, Chungcheongnam-do, Korea \\ ${ }^{1}$ hbramos@kornu.ac.kr, ${ }^{2}$ cyp4x4@kornu.ac.kr
}

\begin{abstract}
Motivational factors and learning styles are significant sources of producing learning outcomes and addressing equity pedagogy among students in a multicultural international business class where multilingualism simply no longer works and learning the global language is a must. This study examined the motivational factors and learning styles significant to global language and business skills acquisition of one hundred business major students. Extrinsic motivation factors (traveling abroad and be able to communicate with business colleagues in the international market) are the most influential factors toward language acquisition and are reflective of students' strong perception of communication skills as the most important dimension in business skills acquisition valuable in an international business field. Learning styles of visual and auditory learners described the business students who gain knowledge production better through sight, spatial understanding, and sound. Finally, a discourse of recommendations for educators is provided to fully utilize the motivation factors and learning styles of business major students towards continuous improvement and increased commitment to quality instruction in multicultural education.
\end{abstract}

Keywords: Motivational factors, Learning styles, Global language, Multicultural, Education

\section{Introduction}

In the context of multicultural business education, educators are driven by a persistent desire to seek continuous improvement of their classroom experiences. In committing to creative design to address equity pedagogy, many engage in strategies that place high premiums to a learner as a central feature to a specific approach to language acquisition, knowledge creation, and skills development. Some of the major issues incorporated in multicultural education that need to be assessed particularly in the acquisition of English as a global language are motivational factors. A learner is either intrinsically or extrinsically motivated towards achieving a goal and learns best at his or her preferred learning style. Various researches have established knowledge of motivation factors and learning styles to be influential factors in the learning process. These are two vital entities that reinforce the learner's potential and help them meet the demands of required commitment to learning excellence of analogous skill acquisition. However, in the spotlight of multiculturalism where learning the global language is jointly embedded in learning business skills, the knowledge

Article History:

Received (October 28, 2019), Review Result (December 12, 2019), Accepted (January 13, 2020) 
acquisition process becomes an important dimension that emphasizes students to recognize and assess their views, and biases within self-control that may better influence their goals in learning both language and business skills. Thus, this study aims to deal with multicultural business major students in two respects: to assess motivational factors and learning styles as two interdependent learning components as well as to increase awareness of how business major students perceive, process, and interpret knowledge production that can be applied to improve quality instruction particularly in a multicultural education that points at two specialized skills, English language acquisition, and business skills development.

\section{Literature research and analytical framework}

\subsection{Motivation factors}

Motivation is a key factor in learning and must be sustained throughout the learning period to help learners cope with challenges in acquiring business global language and business skills. Students are likely to be intrinsically motivated if they attribute their educational results to factors under their control and believe they can be effective agents in reaching the desired goal [1]. Intrinsic motivation was found to be the most influential factor in secondlanguage learning skills and building their confidence [2]. Extrinsic motivation comes from the outside of the individual such as rewards, coercion, and punishment. Learning motivation will determine students' learning behavior to achieve certain goals [3].

\subsection{Learning styles}

Individuals excel at different things and it is vital to understand the strengths of a learner. Howard Gardner's Multiple Intelligence research identified four (4) types of learning styles: visual learners who learn through sight, auditory learners who learned subject matter better when reinforced by sound, kinesthetic learners, or "tactile" learners who learn better through experiencing or doing things, and reading/writing learners who prefer to learn through written words [4]. The Learning Style Model that was developed by Dunn and Dunn categorized learners based on the classification of individuals as visual, auditory, or kinesthetic learners. In the study conducted by Naik, about 150 students in the College of Business results showed that the majority of them prefer visual and sequential learning [5]. By understanding the student's process of learning and thinking, it can be more efficient in learning and instruction $[6]$.

\subsection{Language acquisition as a skill learning}

On the global scale, all the skills that are mandatory in today's business market are a strong command of the English language [7]. The ability to acquire English as the global language of business is a challenge of skill learning, multifaceted and complex learning on how to use the language effectively, not just for social interactions in a multicultural education but rather, in theoretical and business contexts. The process uses similar mechanisms to those involved in learning to ride a bicycle, play a musical instrument or draw a picture [8]. Converting the primary language of non-native speakers to an international standard is no small task as it calls for adopting the shift and responsibility to comply with the global language framework, policy, and guidelines [9].

Overall, the research presented that indicated knowledge of motivation factors and learning styles are influential factors in the learning process. In this study, the roles of these influential 
factors are continually assessed in a multicultural education that aims at two specialized skills, the acquisition of global language and business skills.

\section{Research method}

The study population was composed of one hundred (100) International Business Management students that come from four years levels in a multicultural department $(72 \%$ Korean students and 28\% International students from the United States, Nigeria, Cameroon, Uganda, Philippines, Nepal, Myanmar, and China). This is the only department in the University that provides all courses in English as a medium of instruction to cater to multicultural education. To generate data, a survey questionnaire was distributed with twenty (20) declarative questions of motivation factors (ten for each intrinsic and extrinsic factors), sixteen (16) declarative questions of learning styles from which four questions were classified in each of the four (4) types of learners: visual, auditory, kinesthetic and reading/writing in a five-point scale namely 5=strongly agree (SA), 4=Agree (A), 3=Neither (N), 2=Disagree (D), $1=$ Strongly Disagree (SD). Two supplementary parts of the questionnaire were given to help the students assess their strengths in English-language-skill learning and required them to rank six (6) important business skills based on how the student perceives from the most important skill to learn to the least. The results derived were analyzed and interpreted through basic descriptive statistics that set preliminary results only that can further be analyzed in future studies.

\section{Results and analysis}

\subsection{Motivation factors}

In [Figure1], two of the highest motivation factors of IBM students in global language acquisition are extrinsic (55\% for MS\#4, "learning English is important in traveling, MS\#13, "learning English will enable me to communicate effectively and accurately with colleagues and guests in business") and (54\% MS\#20 learning English to achieve competitive communication skills in International Business"). Results showed that IBM students were motivated to acquire global language for future rewards and the purpose of their future communication engagement with international colleagues and transactions. (MS= Motivation Sentence)

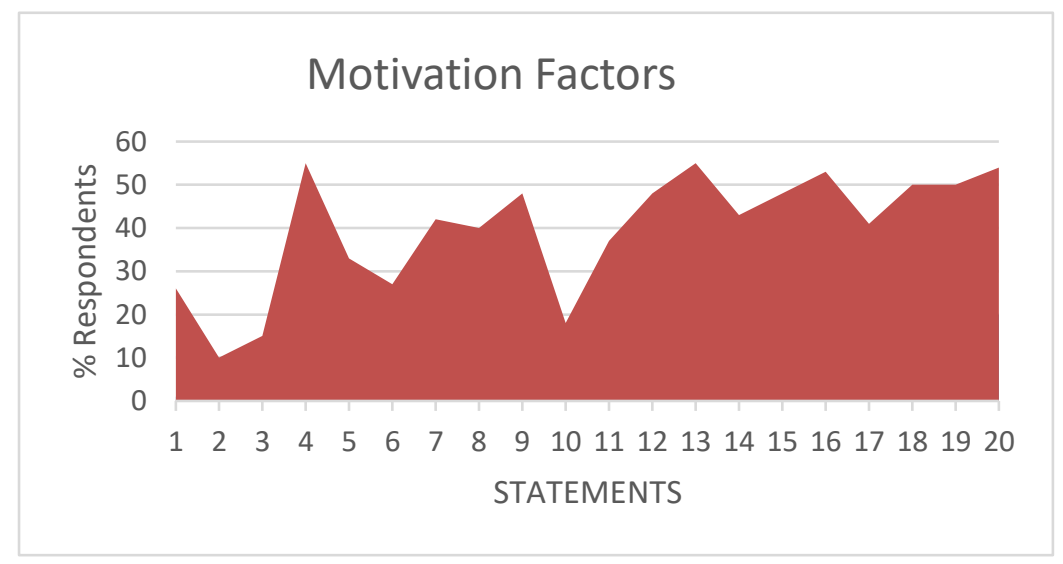

Figure 1. Motivation factors 
Table 1. Sentences for motivation factors

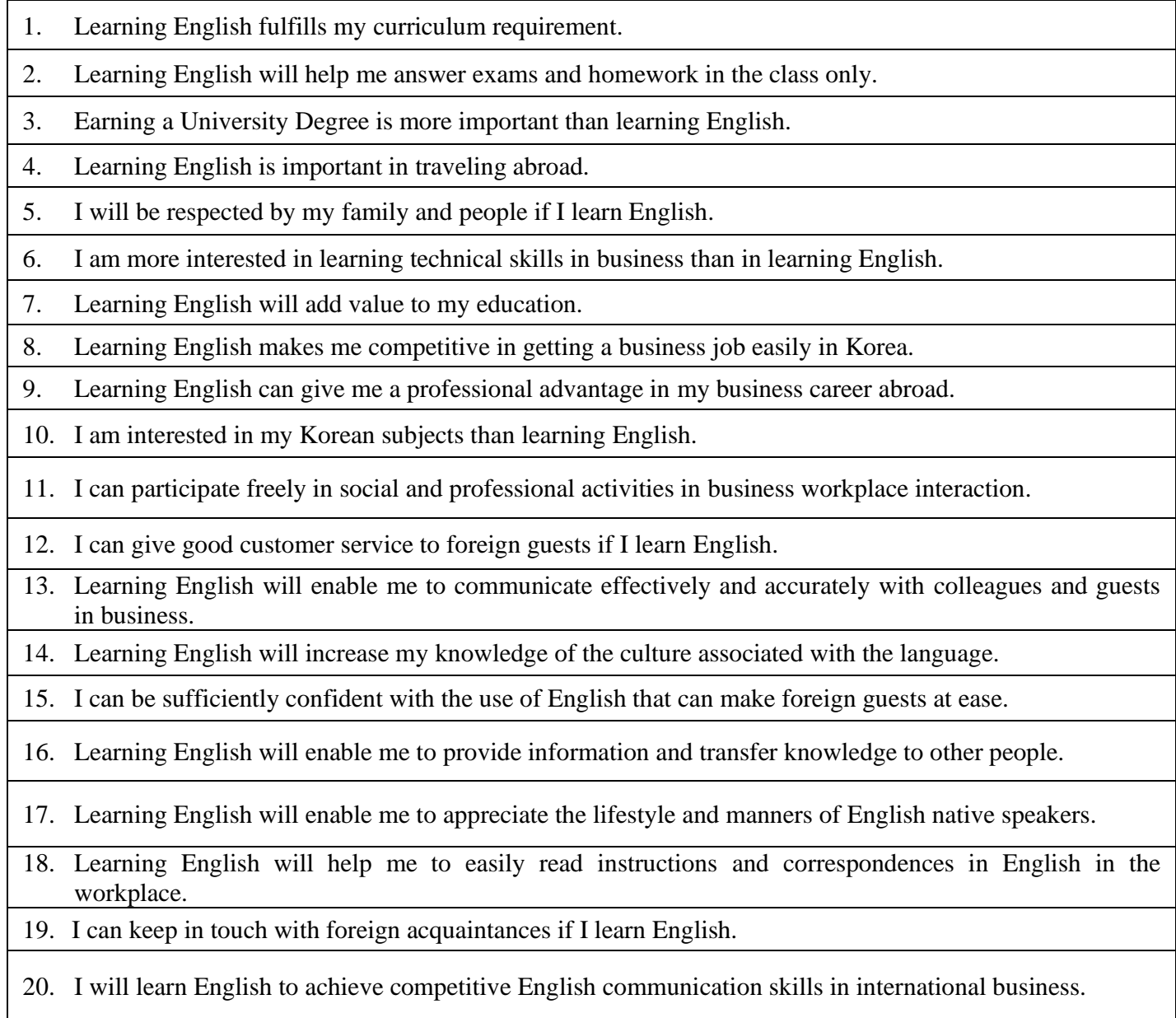

\subsection{Learning styles}

In [Figure 2], the reflected high scores of $45 \%$ for LS\#1, "I look at the teacher's face when teaching", and $34 \%$ for LS\#7, "I like to solve problems by talking about them with my teacher", described IBM students to be visual and auditory learners. They assessed themselves as better learners when they see objects and visual demonstrations and hear direct and clear instructions. A notable result of low result of $20 \%$ on LS\#15 "I enjoy making demonstrations and presentations" is reflective of students' less interest in displaying skills in front of the class, thus, it may cause less cooperation and enthusiasm in this kind of classroom learning dimension. (LS= Learning Style Sentence) 


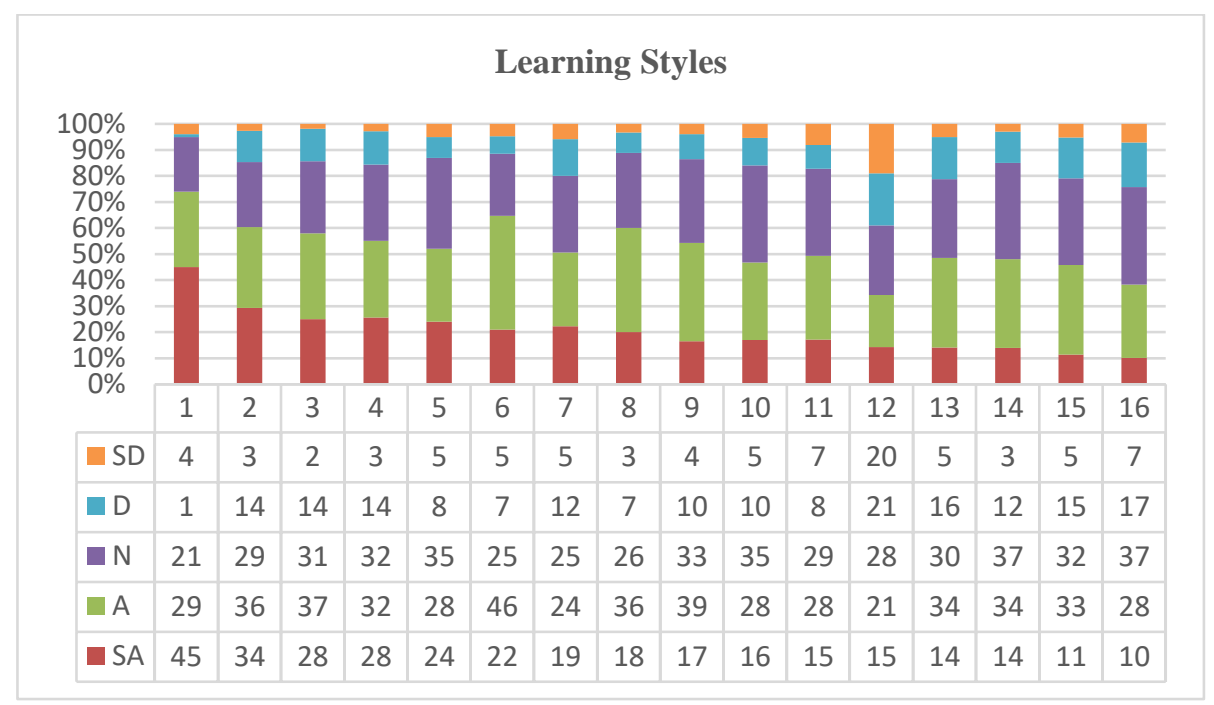

Figure 2. Learning styles

Table 2. Sentences for learning styles

\begin{tabular}{|ll|}
\hline 1. & I look at the teacher's face when teaching. \\
\hline 2. & I like looking at drawings or books when studying English. \\
\hline 3. & I recall information or words by remembering objects or how it was set on a page. \\
\hline 4. & I can easily organize my thoughts using lists. \\
\hline 5. & I enjoy dialogues and discussions in learning English in the class. \\
\hline 6. & I use sound to help me memorize words in English. \\
\hline 7. & I like to solve problems by talking about them with my teacher. \\
\hline 8. & I like to listen when the teacher provides verbal instructions in the class. \\
\hline 9. & I use movement or gesture as a memory aid in learning English. \\
\hline 10. & I learn best when I am involved or active in a workshop in an English class. \\
\hline 11. & I enjoy an English class when there are games and other creative activities. \\
\hline 12. & I find it difficult to sit in an English class for long period. \\
\hline 13. & I enjoy writing English words and sentences. \\
\hline 14. & I learn well in hands-on activities like projects. \\
\hline 15. & I enjoy making demonstrations and presentations. \\
\hline 16. & I use drawings as memory aids in learning English. \\
\hline
\end{tabular}

The chart showed low rates of statements classified as kinesthetic and reading/writing learning methods (LS\#12 "I find difficult to sit in an English class for a long period", LS\#13 "I enjoy writing English words and sentences", LS\#14 "I learn well in hands-on-activities like projects", LS\#15 "I enjoy making demonstrations and presentations", LS\#16 "I use drawings as memory aids in learning English"). However, it is interesting to note that business students are partly kinesthetic learners (28\% in LS\#11, "I enjoy a class when there are games and other creative activities"). There is an implication that experiential or simulation activities related to business skills and knowledge production interest them. 


\subsection{Language skills and business skills}

Students further assessed themselves in language skills acquisition: listening, reading, writing, and speaking. [Figure 3]. reflected that IBM students excel the most in speaking skills in language acquisition. The multicultural composition where English is the common language to communicate continues to enhance their speaking skills in practical conversations. However, students assessed themselves as poor in speaking English when answering or asking questions to the professor. The shift of language of non-native speakers is no small task due to the double cognitive dynamics of learning the business concepts and the global language for expression and interpretation of information.

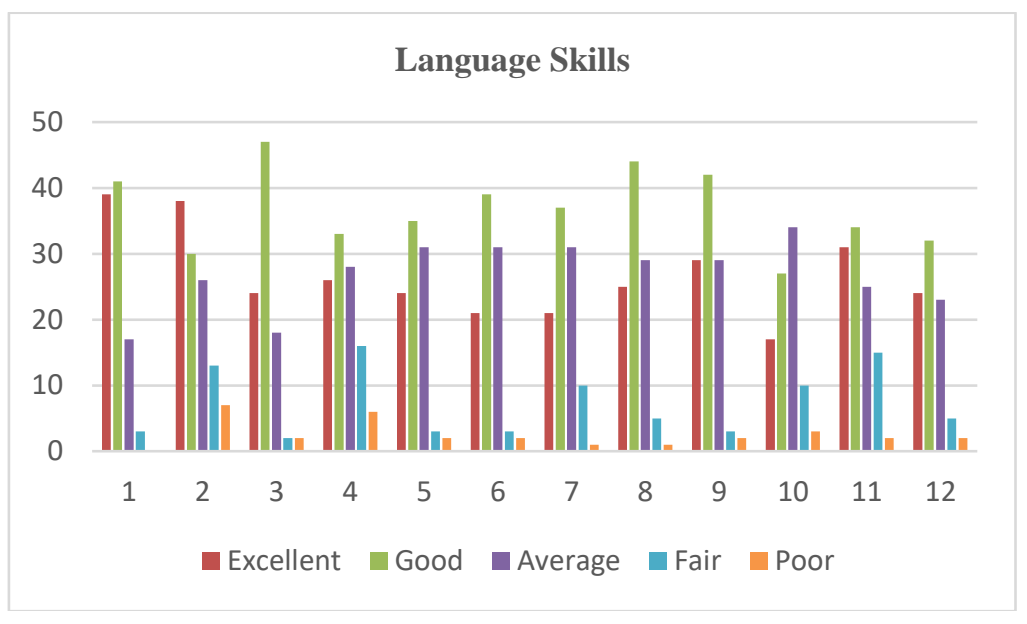

Figure 3. Language skills

Among the considered core of business skills that encompass work, communication, people, customer, analytical and creative, and business operations and management skills, students perceived communication skills as the most important skill they seek to achieve. Second, is a people-oriented skill that enables them to engage in business collaboration, and followed by operations and strategic management, the nuts-and-bolts of a business framework, process, and behavior. Analytical and creative skills and customer-oriented skills (specialized) are the least important to them.

\section{Conclusion and recommendations}

In pursuit of global language and business skills acquisition, extrinsic motivation factors such as rewards to travel abroad and communicate with colleagues in the international business market are the most influential factors in the learning dimension. This finding sets a different view from researches that show the majority of business major students are intrinsically motivated. The majority of IBM students are visual and auditory learners and partly kinesthetic towards experiential learning in knowledge production. Speaking skills are strongly perceived as their strength in learning global language due to multicultural environment that forcibly places English as a common language for communication and collaboration. However, there is a struggle with the expression and interpretation of information in classroom learning due to the shift of language framework particularly to nonnative speakers. 
Here are some recommended actions for educators to utilize and enhance the positive attributes of students as well as the adverse: 1. Extrinsic factors- highlight other rewards (e.g. employability, competitiveness) to widen the range of perceived future benefits; 2. Visual and Auditory learning styles - increase the use of visual materials and provide hours for special mentoring for positive reinforcement of speaking skills and interpret information in business contexts; 3. Partly kinesthetic learners - prepare a creative design to instruction that will provide more experiential learning; 4. Poor writing Skills - incorporate rich-learning activity of technical and business writing. The motivational factors that keep IBM students to pursue an excellent level of global language acquisition and learning styles are key ingredients to produce learning outcomes in both language and business skills acquisition in multicultural education.

\section{References}

[1] H. Tohidi and M. M. Jabarri, "The effects of motivation in education," Procedia Social and Behavioral Sciences, vol.31, pp.820-824, (2011) DOI: 10.1016/j.sbspro.2011.12.148

[2] J. G. Puyo, "Motivational factors in learning an L2: A study on intrinsic/extrinsic motivation, classroom materials and teachers," Behaviors, Research Gate, (2018)

[3] M. K. Tokan and M. M. Imakulata, "The effect of motivation and learning behavior on student achievement," South African Journal of Education, vol.39, no.1, (2019)

[4] E. Lauren, "4 types of learning styles: How to accommodate a diverse group of students," Rasmussen College, (2018)

[5] C. Y. Wu and D. E. Fazarro, "Investigation of learning style preferences of business students," Online Journal for Workforce Education and Development, vol.6, no.2, (2013)

[6] L. Becton, "Discover your learning style - a comprehensive guide on different learning styles," Education Corner, (2019)

[7] D. Weedmark, "Importance of English in business communication," Bizfluent.com, https:// /bizfluent.com/ (2020)

[8] N. Chater and M. Christiansen, "Language acquisition as skill learning," current opinion in behavioral sciences, vol.21, pp.205-208, (2018) DOI: 10.1016/j.cobeha.2018.04.001

[9] N. Tsedal, “Cross-cultural management," Global Business Speaks, May Issue, (2012) 


\section{Authors}

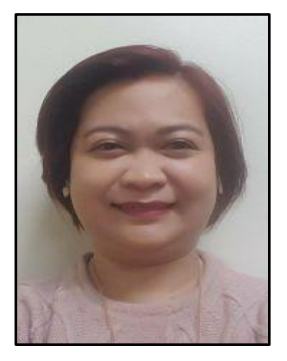

\section{Ramos, Ma. Hazel}

Apr 2009: UP School of Labor and Industrial Relations, DipIR (Postdiploma)

Nov. 2010: UP School of Labor and Industrial Relations, MIR.

Nov. 2010 - Jan 2014: Lyceum of the Philippines, Asst. to the Dean/Faculty Dev't Head

Feb 2013 - Mar 2014: Gyeongju University, Exchange Professor/ HR Head for International Professors

Mar. 2014 current: Korea Nazarene University., International Business Management, Asst. Professor

[Research Interests] Human Resources and Organizational Behavior, Language Education, Tourism Dev't and Management, International Business Management

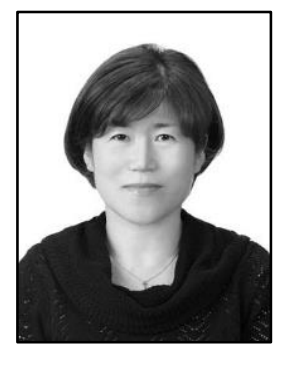

\section{Park, Chung Yeol}

Feb. 1992: Sookmyung Women's Univ., English Literature, MS

Dec. 2004: Oklahoma City Univ., TESOL, MS

Dec. 2014: Hanyang Univ., International Business, MBA

Feb. 1999: Sookmyung Women's Univ., English Literature, Ph.D.

Jan. 2007 Dec. 2008: California State Univ., Dept. of Education, Visiting Professor

Aug. $2009 \sim$ current: Korea Nazarene University., International Business Management, Associate Professor

[Research Interests] Language Education, Business Model, Business Management, International Business Management 